\title{
Mandibular Langerhans cell histiocytosis in an adult
}

\author{
Zajko J \\ Department of Oral and Maxillofacial Surgery, Comenius University, University Hospital, Ruzinov, \\ Bratislava, Slovakia. zajko.juraj@gmail.com
}

\begin{abstract}
Langerhans cell histiocytosis (LCH) in the mandible is a rare disease. $\mathrm{LCH}$ was formerly known as histiocytosis $\mathrm{X}$. Histiocytosis $\mathrm{X}$ is a granulomatous condition that derives form a clonal proliferation of histiocytes. It has a variable clinical course. LCG may be local or disseminated. It is a reactive disorder or a truly malignant process. This article describes a case of a 45 - year old man with Langerhans cell histiocytosis in his jaw (Fig. 4, Ref. 11). Full Text in PDF www.elis.sk.

Key words: Langerhans cell histiocytosis, histiocytosis X, mandible, panoramic examination.
\end{abstract}

In literature, the Langerhans cell histiocytosis $(\mathrm{LCH})$ is described as a rare proliferative disorder, previously known as histiocytosis X. The term "histiocytosis X "was used and first time described by Lichtenstein in 1953 (10). LCH is usually seen in infants, children and young adults in age less than 18 years old. This article describes a case with LCH in the mandible in an adult.

Morphologically, LCH comprises three similar lesions. Eosinophilic granuloma, Hand-Schuller-Christians syndrome and Abl-Letterer-Siwe syndrome $(5,10)$. The exact aetiology of LCH is still unknown. The most frequent sites of bony lesions are the skull, femur, mandible, pelvis and spine (11). Single or multiorgan damage may be seen in liver, spleen, lungs, skin, bone marrow, spinal, central brain and digestive tract $(1,10)$. Clinical manifestation is characterised with different and various forms and stages. The stages in the condition have been classified as follows (3):

Stage I: A Single bone lesion.

Stage II: Multiple bone lesion (previously eosinophillic granuloma-EG).

Stage III a: Bone and soft tissue lesion (previously HandSchuller-Christian disease).

Stage III b: Damage soft tissue only - disseminated form (previously Letterer-Siwe disease).

\section{Case report}

The first examination of the patient was ten years ago. He had recurrent inflammation on the mucosa alveolar arch in the oral cavity. Previous history of the disease was negative. He denied any history of fever, allergy or other diseases. Patient was in good condition and general physical examination was normal. Intraoral examination confirmed only devital canine tooth, second

Department of Oral and Maxillofacial Surgery, Comenius University, University Hospital, Ruzinov, Bratislava, Slovakia

Address for correspondence: J. Zajko, MD, Department of Oral and Maxillofacial Surgery, Comenius University, University Hospital, Ruzinov, Ruzinovska 6, SK-826 06 Bratislava, Slovakia

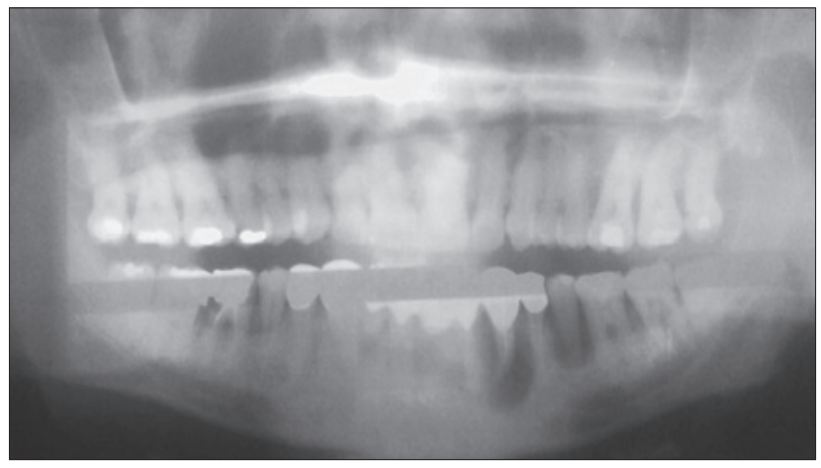

Fig. 1. Primary status before first operation.

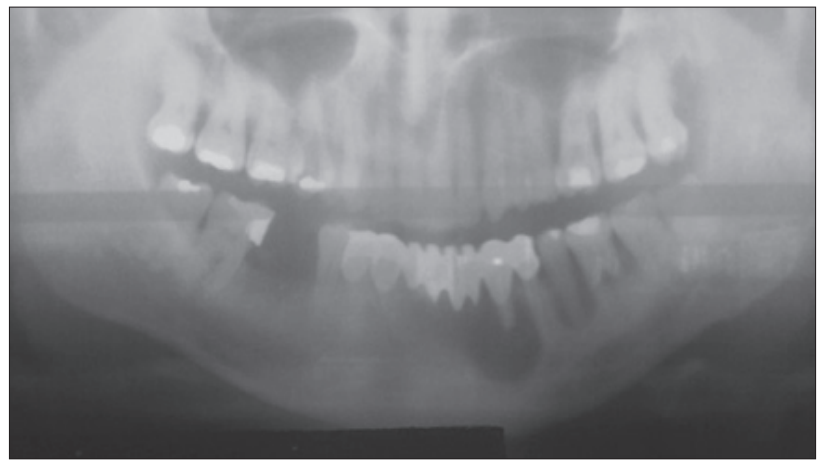

Fig. 2. Status after first operation.

premolar on left side and first molar on right side as well. There were deep periodontal and dental pockets. Jaw panoramic examination showed a cystic lesion on left mandible part under canine tooth and second premolar on left side and devital first molar on the right side (Fig. 1). Cystic process was removed by surgery procedure. The first molar on the right side was extracted as well. He didn't agree with removing his second premolar on left side. Wound healing was without problem. Cystogranuloma mandible was confirmed by a biopsy (Fig. 2). 


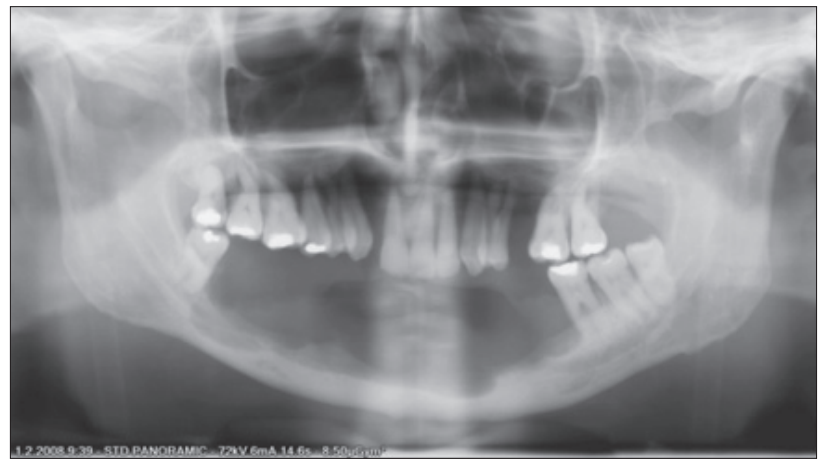

Fig.3. X ray after second operation.

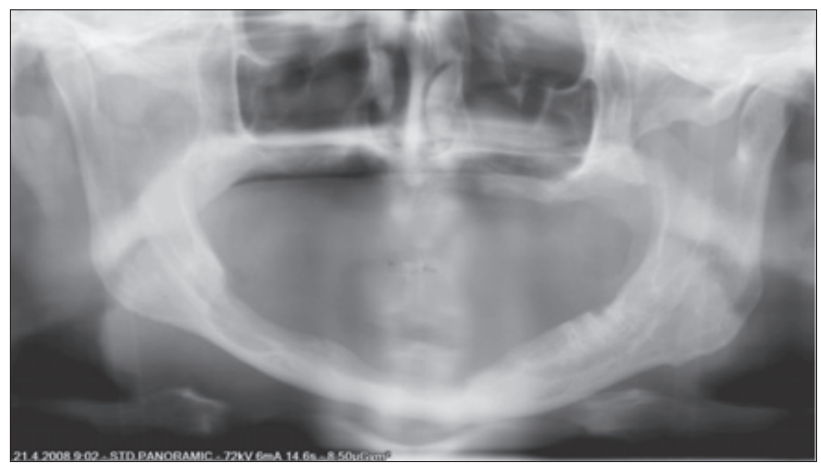

Fig. 4. Current status of the patient. Severe jaw atrophy of alveolar bone.

After five years, the patient came unexpectedly with an advanced inflammation of marginal mucosa, periodontal pocket size from 3 to $5 \mathrm{~mm}$ around whole dentition with moving. X-ray examination showed many shadows and translucency around the teeth. Generally, periodontal process was confirmed by clinical examination. He didn't agree with a radical therapy again. So we removed only the teeth on left down mandible (Fig. 3). Detected granular tissue was removed by curettage after an extraction. Biopsy examination confirmed the presence of Birbeck granules under an electron microscopy and imunohistochemical staining with S 100 protein confirmed also antibody CD-1a and Vimetin. The conclusion of biopsy was Langerhans histiocytosis of mandible.

Patient was examined also on the internal department. Examination of liver, lungs, spleen, kidney, long bones was negative. The physician at the internal department recommended antibiotic therapy with Klimynin and Dalacin C.

Then, the patient was recommended to the clinical oncology department. The treatment consisted of metylpredison and vinblastin (Fig. 4). It was an unbelievable diagnosis for us.

The process progressed after six months. There was inflamed red musoca in many parts around the dentition and teeth were loose. The tissue after extraction was examined and the biopsy results again confirmed LCH disease. In mandible and maxilla, severe atrophy has arisen. The patient is in systematic medical care now. After the stabilization, out plan is to use bone graft to alveolar arch mandible and maxilla.

\section{Discussion}

The aetiology of LCH is not exactly known. Literature describes genetics components, the immune system's immaturity and neoplasm or some kind of infectious disease. New knowledge described an abnormal immunological answer to virus infection of lymphocytes especially HHV-6 (4).

The incidence of LCH is 1:1500 000 inhabitants, other literature source states 1:560 000 (5). WHO described 5:1 000000 and German literature 1-2:1 $000000(1,7,11)$. More frequent is in male than in female. The reported ratio ranges from 2:1 to 4:1 (5). A skeletal lesion of LCH can occur in any bone. The most common are pelvis, ribs, skull, long bones, vertebra and facial bones. The incidence in jaws is $7.9 \%$ (5).

If the LCH occur in an adult, clinical lesion is $80 \%$ in bone, $60 \%$ skin, $33 \%$ liver, spleen and lymphatic system, $30 \%$ bone narrow, $25 \%$ lung and $20 \%$ oral space with loosing the teeth (1, 10). There are different stages of disease in adulthood.

Osteolytic defects are basically in the axis skeleton, less in periphery. Bone deposit is in calva region in $51 \%, 30 \%$ in mandible and maxilla, $17 \%$ in long bone, $13 \%$ in vertebra and $6 \%$ in the ribs $(1,3,6,11)$.

Clinical symptoms are different. They depend on the locality and organs damaged. Progressive form may be fatal. An isolated form has a better prognosis than the osteolytic form with disseminated eosinophilic granuloma (EG). The children from two years of age may be damaged with progressive form of $\mathrm{LCH}$ and disseminated form with an acute and subacute process may be often fatal. The disseminated, chronic form is called the Hand-Schueller-Christian syndrome. It consists of skeletal and extra skeletal lesion and usually affects children older than 3 years of age with a progressive chronic course. The disseminated acute or subacute form is called Alb-Letterer-Siwe syndrome. Also it is referred as the disease that is most often fatal. This form usually affects infant and children younger than 3 year age (5).

The disease is characteristic by a pathologic proliferation of Langerhans cell (LCH) with accumulation of eosinofilic granulocytes, histiocytes and macrophags $(3,5)$. The diagnosis of LCH can be confirmed by the presence of Birbeck granules or by immunohistochemical staging with CD-1a and S-100 protein $(2,6,7,9,11)$.

The oral findings are important in LCH. The most common oral findings are pain, swelling, ulceration on oral mucosa, gingival necrosis with the movement of teeth and alveolar bone destruction. The patients have rarely systematic symptoms and many lesions are asymptomatic. $\mathrm{X}$ ray examination shows bony destruction in the jaw with a number of well-define radioluscencies. There may be severe alveolar bone resorption (8).

This disorder may be easily mistaken with common dental disorders like periodontitis or periodontal dental progress. These signs and symptoms include pain, the presence of pathologic mass as gingival necrosis with ulceration, poor healing and destruction of alveolar bone in various part on alveolar bone and related bleeding and loose teeth, paresthesia and difficulty in chewing (3). Radiographically, mandibular lesion of LCH is usually seen as area of osteolysis inside or close to the alveolar process. The 
$488-490$

lesion usually destroys the periodontal bony support of multiple teeth (10).

Clinical prognosis of $\mathrm{LCH}$ varies from spontaneous resolution to death. Bony lesion is usually self-limiting process. Treatment modality is still not standardized. Treatment modalities for $\mathrm{LCH}$ are variable according to localization and number of lesions. Surgical treatment consists of local excision and curettage, with or without bone grafting. Radiotherapy and chemotherapy can be used alone or in combination. Radiotherapy is a controversial treatment. Chemotherapy is suggested for the disseminated LCH such as multiple bone lesion or multisystem disease. The recurrence rates depend on the treatment method and location of the lesion. The reported range is from 1,6 to $25 \%$ (8). We performed a radical tooth extraction in our patient, than curettage of tissue and chemotherapy in the oncological department.

\section{Conclusion}

The aim of this article was to give a short report and overview on diagnosis and treatment of LCH in the maxillofacial region and present a case report of the patient.

The Langerhans cell histiocytosis is a very unusual diagnosis and rare in an adult. We established this diagnosis for the first time. Treatment is difficult, relapses are frequent. Diagnosis must be confirmed by a biopsy examination. Therapy must be local and general. Except the local therapy, there must be also the therapy at the oncology department and also organ or multiorgan damage must be evaluated. If LCH is presented in the patient's jaw, there may be loose dentition. Patient has problems with eating and speech. There is a marked atrophy in the jaw bone, also the soft tissue is not in correct position and patient don't have any dental substitute. For the future, situation is also complicated, because we did't do any intervention and patient's oral situation is not good. In this case we must wait for the conclusion of the oncology treatment and if it is be successful, we may try to operate on the patient for better result on bone segment in jaws by bone grafting. The aim of this article was to show an unusual diagno- sis, Langerhans histiocytosis, also in the head and neck region. Diagnosis must be confirmed by biopsy in all difficult periodontal processes. Therefore, in a clinical view, when we see a heavy form like periodontitis or periodontal process, we must think also of Langerhans histiocytosis ( $\mathrm{LCH})$.

\section{References}

1. Adam Z, Pour L, Krejěí M, Hájek R. Histiocytóza z Langerhansových buněk u dospelých osob. Trans Hemat dnes 2008; 14: 110-113.

2. Alajaberg I, Borasc VV, Fomenic R, Arambasin CA, Ancic M, Kekecic J, Aljaberg IZ. Unrecognized oral manifestation of Langerhans cell histiocytosis with progeessed to systemic diseas. Oral Oncol 2006; 42: 10-13.

3. Batra P et al. Langerhans cell histiocytosis - A case report. J Indian Soc Ped Prev Dent 2004; 22 (4): 168-171.

4. Glotzbecker MP, Dormans JP, Pawel BR, Wills BP, Joshi Y, Elkan M, Hodinka RL. Langerhans cell histiocytosis and human herpes virus 6 (HHV-6), an analysis by real-time polymerase chain reaction. J Orthop Res 2006; 24 (3): 313-320.

5. Haberal Can I et al. Oral Oncology. EXTRA 2005; 41: 174-177.

6. Nakamura S, Bessho K, Nakao K, Iizuka T, Scott RF. Langerhan's Cell Histiocysosis Confirmed to the Jaw. J Oral Maxillofac Surg 2005; 63: 989-995.

7. Putters TF, Visscher JG, van Veen A, Spijkvervet FK. Intraoseal infiltration of corticosteroids in the treatment of localised langerhan's cell histiocytosis of the mandible. Int J Oral Maxillofac Surg 2005; 34 (5): 571-575.

8. Ress J, Paterson AW. Langerhans cell histiocysosis in an adult. Brit J Oral Maxillofac Surg 2009; 47: 52-53.

9. Uckan S, Gurol M, Durmus E. Recurrent Multifocal Langerhans Cell Eosinophilic Granuloma of the Jaws: Report of a Case. J Oral Maxillofac Surg 1996; 54: 906-909.

10. Takashi K et al. Langerhans Cell Histiocytosis in the mandible. Oral Radiol 1997; 13 (2): 109 - 114

11. Zeleník K, Mrázková E, Mrázek J. Neobvyklá př́icina zduření v oblasti šupiny spánkové kosti. Pediat pro Prax 2006; 4: 218-219.

Received August 3, 2011. Accepted January 12, 2013. 